\title{
Combustion performance of a novel hybrid rocket fuel grain with a nested helical structure
}

\author{
Zezhong Wang ${ }^{\mathrm{a}, \mathrm{b}}$, Xin Lin ${ }^{\mathrm{a}, *}$, Fei $\mathrm{Li}^{\mathrm{a}}$, Xilong $\mathrm{Yu}^{\mathrm{a}, \mathrm{b}}$ \\ a Institute of Mechanics, Chinese Academy of Sciences, Beijing, 100190, China \\ b School of Engineering Science, University of Chinese Academy of Sciences, Beijing, 100190, China
}

\section{A R T I C L E I N F O}

\section{Article history:}

Received 17 September 2019

Received in revised form 24 November 2019

Accepted 2 December 2019

Available online 5 December 2019

\section{Keywords:}

Hybrid rocket engine

Paraffin-based fuel

Acrylonitrile-butadiene-styrene

Regression rate

Combustion efficiency

\begin{abstract}
A B S T R A C T
The combustion performance of a novel fuel grain having a nested helical structure was experimentally investigated using a laboratory-scale hybrid rocket engine. This grain comprised a paraffin-based fuel embedded in an acrylonitrile-butadiene-styrene (ABS) substrate that provided a helical structural framework. The helical structure of the grain was maintained throughout the combustion process due to the much lower regression rate of ABS compared with that of the paraffin-based fuel. Using oxygen as the oxidizer at mass flow rates of 7-30 g/s, firing tests were conducted to assess combustion performance parameters of the novel fuel grain, including ignition characteristics, pressure oscillations, regression rate, and combustion efficiency. Pure paraffin-based fuel grains were also tested as a baseline fuel and compared. The novel fuel grain exhibited rapid, reliable ignition with stable combustion pressures. Analysis of pressure fluctuations by fast Fourier transform showed peaks at approximately 62, 130 and $320 \mathrm{~Hz}$, which are consistent with the characteristics of a pure paraffin-based fuel grain. It is highly likely that the nested helical structure did not introduce additional combustion oscillation mechanisms into the hybrid rocket engine. Significant improvements in regression rate were obtained using this novel grain. The regression rate for the novel fuel grain is approximately $20 \%$ higher than that of the paraffin-based fuel at an oxidizer mass flow rate of $30 \mathrm{~g} / \mathrm{s}$, and the rate of the regression rate rise was higher than that of the pure paraffin-based fuel as the oxidizer mass flow rate increases. Moreover, the nested helical structure was also found to improve combustion efficiency. A tentative explanation of all improvements was proposed, resorting to the exacerbated turbulence and the strengthened heat transfer.
\end{abstract}

(c) 2019 Elsevier Masson SAS. All rights reserved.

\section{Introduction}

Hybrid rocket engines generally use a solid fuel together with a liquid oxidizer as the propellant. This provides many advantages, such as a simple structure, highly safe operation and manufacture, adjustable thrust and low cost [1-3]. These characteristics have suggested applications to commercial aerospace vehicles, and such low-cost propulsion systems have thus received increasing attention [4-9]. However, the poor combustion performance of conventional hybrid rocket fuels constrains the further development of hybrid rocket engines, such as low regression rates and low combustion efficiencies [10,11].

Low regression rates are a well-known key issue that restricts development of hybrid rocket engines. As a consequence of the relatively slow combustion of fuels such as hydroxyl-terminated polybutadiene (HTPB), conventional hybrid rocket engines require

\footnotetext{
* Corresponding author.

E-mail address: linxin_bit@163.com (X. Lin).
}

two compromises to achieve higher thrust levels, one of which is to increase the burning area of the solid fuel. However, in such cases, the volume utilization efficiency of hybrid rocket engines is decreased even if the length of the fuel grain is increased or if a multiple port structure is used. Moreover, during production or combustion processes, fuel grains with multiport structures are more likely to collapse [1]. Another approach to increasing the regression rate is to increase the mass flow rate of the oxidizer, although this results in high $\mathrm{O} / \mathrm{F}$ ratios that in turn reduce specific impulse and combustion efficiency while increasing nozzle erosion.

Researchers have proposed a variety of solutions to improve the fuel regression rate [12-24]. From the perspective of solid fuel optimization, Cantwell et al. [12] found that paraffin wax and solid pentane exhibited excellent regression rates due to the entrainment of droplets. Based on both experiments and numerical simulations, Carmicino et al. [13] and Sun et al. [14] found that adding solid particles such as aluminum powder effectively improved the regression rate of solid fuels. Hashim et al. [15] demonstrated that addition of titanium and magnesium particles to a boron/HTPBbased fuel augmented its combustion performance. The optimiza- 

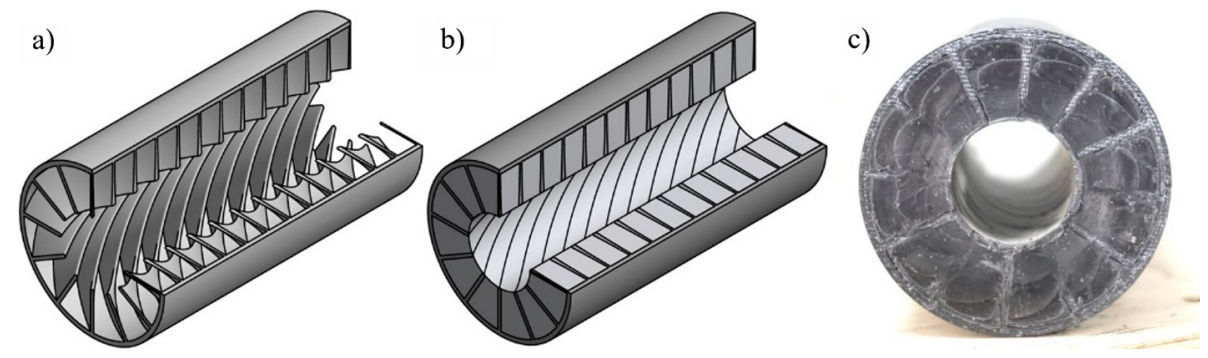

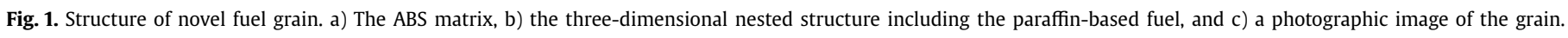

tion of solid fuels in this manner greatly increases the regression rate, but also introduces new problems, such as poor mechanical properties, lower specific impulse values, and greater nozzle ablation.

Low combustion efficiency is another key issue that limits development of hybrid rocket engines. The aforementioned optimization of the solid fuel is unable to change the nature of the large diffusion flame resulting in a lower degree of mixing and lower combustion efficiency. This loss is theoretically $1 \%-2 \%$ greater than in either liquids or solids [1]. As a means of improving the combustion efficiency and increasing fuel regression rate, structural optimization is widely investigated, including that of hybrid rocket engines and fuel grains.

From the perspective of structural optimization of the hybrid rocket engine, Paccagnella et al. [16] demonstrated numerically that use of a swirl injector increased the fuel regression rate and combustion efficiency. Ohyama et al. [17] investigated the effects of multi-section swirl injection on the fuel regression rate and combustion efficiency, while Kumar et al. [18] found that the presence of protrusions enhanced the combustion performance of fuel grain. These structures do significantly improve performance, but typically add mass to the engine that cannot burn to generate gases for propulsion [19].

Structural improvement of the fuel grain, without the above shortcomings, has received attention as another solution to effectively improve the combustion performance [23-39]. For example, Changjin Lee et al. [23] and Hui Tian et al. [24] investigated the effect of the helical grain on the regression rate by experimental and numerical study. The development of three-dimensional (3D) printing technology has assisted in fuel grain research [25-31]. Using this process, it is possible to easily and conveniently produce fuel grain specimens that would be difficult or costly to form by traditional manufacturing methods [32,33]. On this basis, various experimental investigations have examined the combustion performance of different fuel grain structures, such as swirl patterns, helical ports and combined ports, which can greatly enhance combustion performance [34-39]. In particular, Whitmore et al. [34-36] significantly improved the regression rate and specific impulse obtained from acrylonitrile-butadiene-styrene (ABS) grains by adjusting the component proportions, and also obtained better combustion performance from such ABS grain using a helical port structure. However, during the combustion of a hybrid rocket engine, these characteristic structures in the fuel grain gradually disappear, resulting in a slow decrease in performance.

The present work examined a novel fuel grain having a nested helical structure designed to generate turbulence that improves both regression rate and combustion efficiency. This effect was assessed using grains comprising a paraffin-based fuel embedded in an ABS substrate. In this system, the ABS substrate provides a helical structural framework for the paraffin-based fuel. The combustion performance of this new grain was experimentally investigated using a laboratory-scale hybrid rocket engine with oxygen as the oxidizer. Pure paraffin-based fuel grain was tested as a baseline fuel and compared to the novel fuel. The ignition performance was examined by following the evolution of the combustion chamber pressure with time, while oscillations of the combustion pressure were analyzed using a fast Fourier transform (FFT) algorithm to process the pressure data. Both the regression rate and the combustion efficiency of this novel fuel grain were investigated and are discussed in detail herein.

\section{Fuel grain manufacturing}

A nested helical structure was proposed for the solid fuel grain. The basic concept was to take advantage of the different regression rates of $A B S$ and a paraffin-based fuel to maintain the structure throughout the entire combustion process. As shown in Fig. 1, the novel grain consisted of two parts: a substrate having a nested helical structure (Fig. 1a) and the paraffin-based fuel (Fig. 1b). The substrate was made of an ABS material and was fabricated using 3D printing. This component of the grain was meant to provide mechanical support to the paraffin-based fuel and also served as an additional fuel. It comprised an outer wall and twelve integrated blades (thickness $\delta$ is $1.5 \mathrm{~mm}$ ) spiraling in the axial direction. The paraffin-based fuel was the main component of the grain, accounting for $86 \%$ of the total mass (without the outer wall of the novel grain). The mechanical properties of the paraffin were enhanced by incorporating additives such as ethylene vinyl acetate copolymer, stearic acid and carbon powder. The formulation of this fuel has been previously published [40].

Preparation of the grain can be divided into two major stages: 3D printing and centrifugal casting. The substrate was first designed using 3D graphics software and then imported into a 3D printer (Raise3D N2 Plus) for slice printing, using $1.75 \mathrm{~mm}$ commercial ABS consumables as printing material. The hot bed and nozzle were set to temperatures of 100 and $240{ }^{\circ} \mathrm{C}$, respectively, during printing. To shorten the preparation time, the layer height was set to $0.25 \mathrm{~mm}$ although, even so, almost ten hours of printing were required to produce the matrix. In contrast to the typical molding of a paraffin-based fuel grain, which requires a phenolic resin tube as the insulation layer together with a molding die, the printed matrix was not only an important structural component of the novel fuel grain, but could also be used as an insulating material and mold in the subsequent centrifugal casting process. Because the deformation temperature of ABS is approximately $120{ }^{\circ} \mathrm{C}$, the paraffin-based fuel was heated at $120{ }^{\circ} \mathrm{C}$ to prevent deformation of the blades. The centrifuge speed was set to $1400 \mathrm{rpm}$ and a multiple casting method was used in conjunction with effective cooling to minimize thermal stress and prevent internal cracks or defects during the casting process. During casting, the paraffin-based fuel was added until it completely filled the gaps between the blades. The final product, which required approximately $20 \mathrm{~h}$ to prepare in total, is shown in Fig. 1c.

\section{Experimental setup}

The hybrid rocket engine test facility is shown in Fig. 2. The apparatus consisted of a pipeline system, ignition system, hybrid 


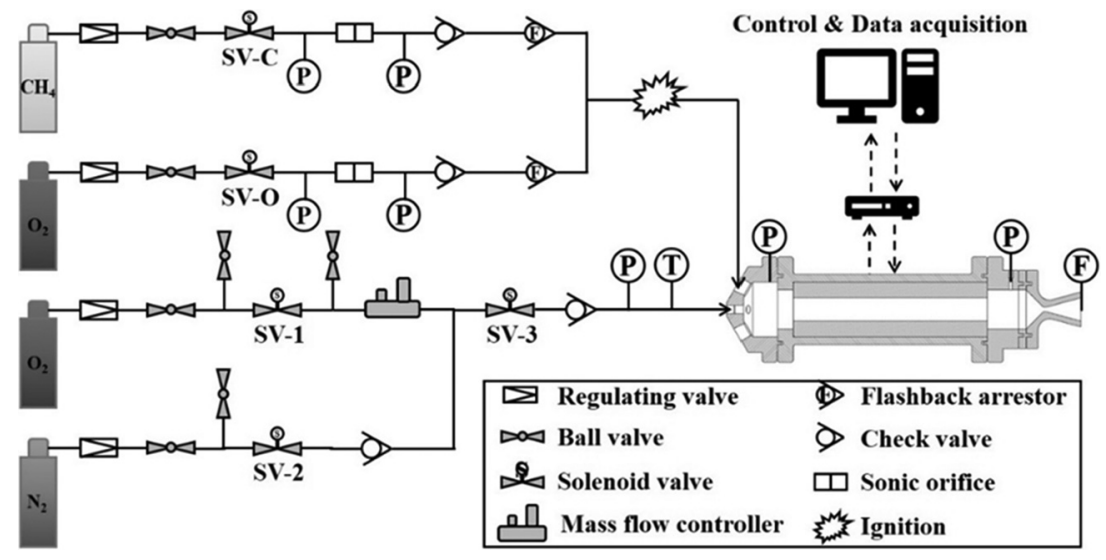

Fig. 2. Laboratory-scale hybrid rocket engine piping system.

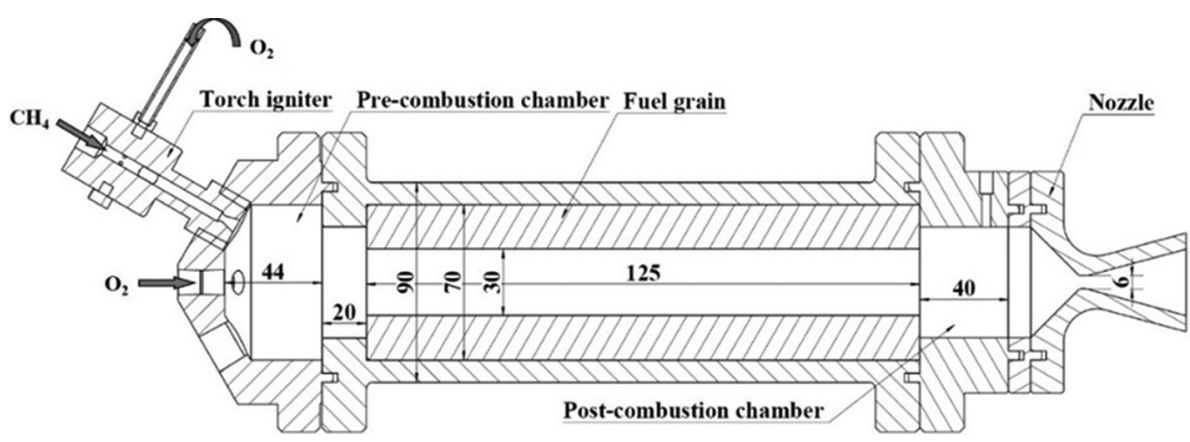

Fig. 3. Schematic of experimental setup for the laboratory-scale hybrid rocket engine tests.

rocket engine and control system. The piping comprised four lines that were used to supply methane for ignition, oxygen for ignition, the oxidizer and nitrogen. Grain ignition was performed using a methane/oxygen torch activated by a conventional spark plug. The total mass flow rate during ignition was set to $3 \mathrm{~g} / \mathrm{s}$ and was controlled by a sonic orifice. The equivalence ratio was set to 1.25 and the ignition time was $2 \mathrm{~s}$. The mass flow rate of the oxidizer was controlled by an F-203AV mass flow controller (Bronkhost) having a maximum flow rate of $35 \mathrm{~g} / \mathrm{s}$ and an accuracy of $\pm(0.5 \%+0.1 \% \mathrm{FS})$. The mass flow rate of oxygen ranged from 7 to $30 \mathrm{~g} / \mathrm{s}$. Nitrogen was used as a purge gas after the hybrid rocket ceased operation.

The laboratory-scale hybrid rocket engine used in this work is shown in Fig. 3. The igniter and oxidizer inlet were positioned at the head of engine. The length of the main combustion chamber was $125 \mathrm{~mm}$, which was equal to the length of the fuel grain. The fore and aft ends of the combustion chamber had lengths of 20 and $50 \mathrm{~mm}$, respectively. The inner diameter of the engine was 70 $\mathrm{mm}$ and the inner diameter of the bore in the solid fuel grain was $30 \mathrm{~mm}$. Chamber pressure was monitored by installing two ports in the pre and post combustion chambers. A conical nozzle with a throat diameter of $6 \mathrm{~mm}$ was employed.

The control system consisted of an NI board, an industrial computer and a control program. The engine was remotely controlled and data were acquired using a control program installed on the computer, based on the LabVIEW software package. The data acquisition frequencies were 100 and $1000 \mathrm{~Hz}$. The sequential control of the system is summarized in Table 1 . The firing test and data collection began at $t=0 \mathrm{~s}$; at $t=5 \mathrm{~s}$, the oxidizer mass flow controller was activated to establish a stable back pressure; ignition occurred at approximately $t=8 \mathrm{~s}$; at $t=18 \mathrm{~s}$, the oxidizer supply was stopped and the engine turned off. The total experimental time was $40 \mathrm{~s}$.
Table 1

Timing control during testing of the lab-scale hybrid rocket engine.

\begin{tabular}{lll}
\hline Serial number & Time, s & Action \\
\hline 1 & 0.0 & Turn on data acquisition \\
2 & 3.0 & Open SV-1 and SV-3 \\
3 & 5.0 & Open mass flow controller \\
4 & 7.0 & Spark plug discharge \\
5 & 8.0 & Open SV-C and SV-O \\
6 & 9.0 & Close SV-C and SV-O, turn off power of ignition \\
7 & 18.0 & Close SV-1 and mass flow controller \\
8 & 19.0 & Open SV-2 \\
9 & 39.0 & Close SV-2 and SV-3 \\
10 & 40.0 & Turn off data acquisition \\
\hline
\end{tabular}

\section{Results and discussion}

Over 35 firing tests were conducted to investigate the combustion performance of the grains with nested helical structures. The combustion performances of the paraffin-based fuel grain and a 3D printed fuel grain made solely with ABS were also assessed for comparison purposes. The resulting data were analyzed to assess ignition performance, pressure oscillations, regression rate and combustion efficiency. The results are presented in Table 2.

\subsection{Ignition}

Reliable ignition together with stable combustion are necessary for any rocket engine. Fig. 4 presents a series of photographic images showing the functioning of the laboratory-scale hybrid rocket with the novel fuel grain, including ignition, flame development and flameout. During the initial ignition stage, the Mach ring at the nozzle outlet was clearly visible. With the development of full combustion, a bright flame appeared that was evidently stable as it grew. 
Table 2

Summary of test results.

\begin{tabular}{|c|c|c|c|c|c|c|}
\hline No. & Materials & Mass flow rate of oxidizer, g/s & Thrust, kg & Combustion pressure, $\mathrm{MPa}$ & $\mathrm{O} / \mathrm{F}$ & Structure \\
\hline 1 & ABS fuel + Paraffin-based fuel & 20.5 & 6.4 & 1.47 & 1.9 & 12 blades with helical structure \\
\hline 2 & ABS fuel + Paraffin-based fuel & 23.7 & 7.8 & 1.63 & 2.2 & 12 blades with helical structure \\
\hline 3 & ABS fuel + Paraffin-based fuel & 19.0 & 6.5 & 1.39 & 2.0 & 12 blades with helical structure \\
\hline 4 & ABS fuel + Paraffin-based fuel & 14.4 & 5.0 & 1.10 & 1.8 & 12 blades with helical structure \\
\hline 5 & ABS fuel + Paraffin-based fuel & 7.1 & 2.7 & 0.58 & 1.2 & 12 blades with helical structure \\
\hline 6 & ABS fuel + Paraffin-based fuel & 9.5 & 3.3 & 0.72 & 1.5 & 12 blades with helical structure \\
\hline 7 & ABS fuel + Paraffin-based fuel & 28.9 & 9.7 & 2.06 & 2.6 & 12 blades with helical structure \\
\hline 8 & ABS fuel + Paraffin-based fuel & 27.8 & 8.9 & 1.89 & 2.3 & 12 blades with helical structure \\
\hline 9 & Pure ABS fuel & 21.5 & 3.8 & 1.54 & 4.3 & Single hole \\
\hline 10 & Paraffin-based fuel & 21.7 & 6.2 & 1.40 & 2.5 & Single hole \\
\hline 11 & Paraffin-based fuel & 25.7 & 8.2 & 1.79 & 2.6 & Single hole \\
\hline 12 & Paraffin-based fuel & 14.3 & 5.0 & 1.07 & 1.8 & Single hole \\
\hline 13 & Paraffin-based fuel & 18.6 & 6.4 & 1.36 & 2.1 & Single hole \\
\hline 14 & Paraffin-based fuel & 9.5 & 2.8 & 0.70 & 1.5 & Single hole \\
\hline 15 & Paraffin-based fuel & 12.0 & 3.5 & 0.85 & 1.8 & Single hole \\
\hline 16 & Paraffin-based fuel & 25.6 & 8.3 & 1.68 & 2.8 & Single hole \\
\hline 17 & Paraffin-based fuel & 24.8 & 7.6 & 1.65 & 2.7 & Single hole \\
\hline
\end{tabular}

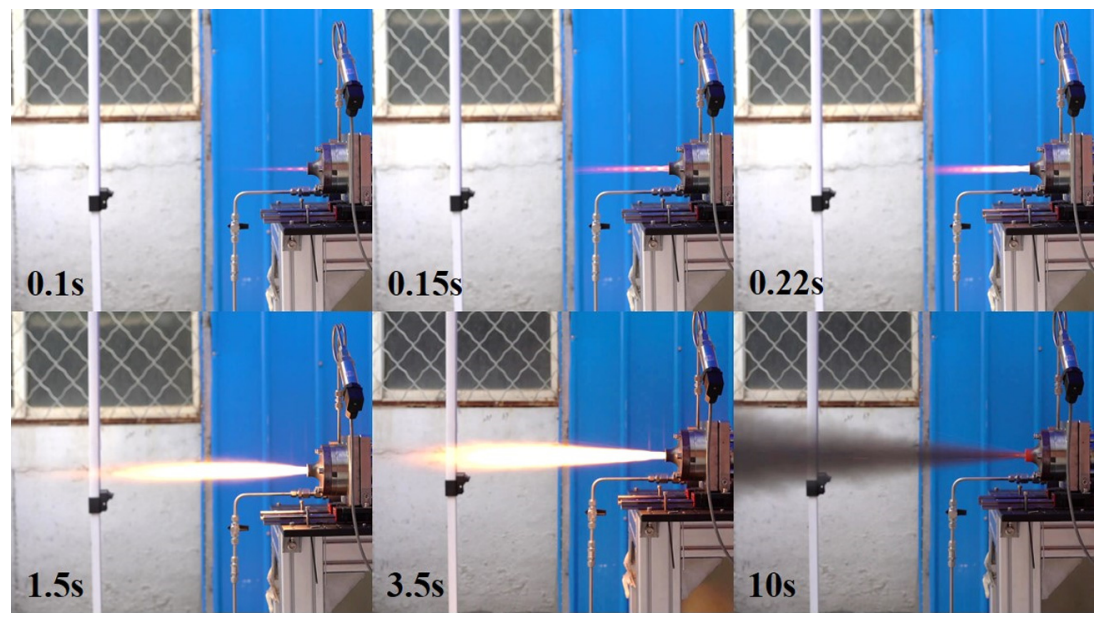

Fig. 4. Images showing laboratory-scale hybrid rocket engine firing test employing the novel fuel grain.

a)

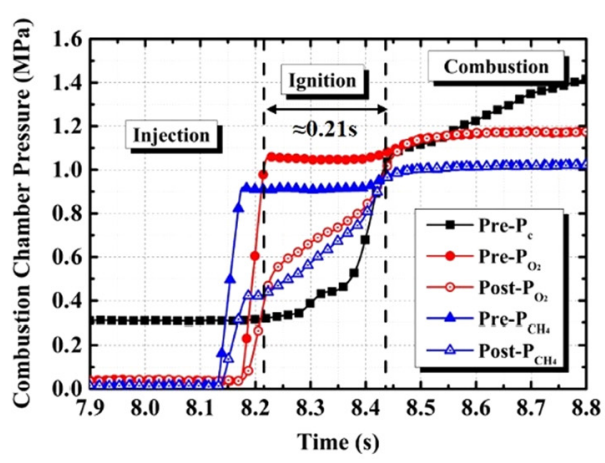

b)

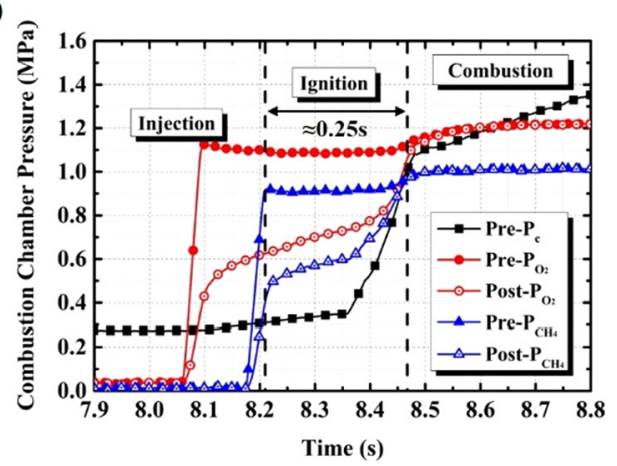

Fig. 5. Time histories of chamber pressure from typical firing tests using a) the novel fuel grain and b) the paraffin-based fuel grain.

The ignition performance of the novel fuel grain was examined by assessing the evolutions of pressure during combustion of the new grain and of a paraffin-based fuel grain, which are compared in Fig. 5. At approximately $8.2 \mathrm{~s}$, the solenoid valves providing the methane and oxygen opened and the $\mathrm{CH}_{4} / \mathrm{O}_{2}$ torch was activated. After approximately $0.2 \mathrm{~s}$, the combustion chamber pressure rapidly increased to $1 \mathrm{MPa}$, indicating successful ignition. At approximately $8.5 \mathrm{~s}$, the two sonic orifices that controlled the mass flow rates of methane and oxygen failed due to the increased back pressure.

In the case of the paraffin-based fuel grain (Fig. 5b), the entire ignition process was smooth and rapid, demonstrating that both novel fuel grains and paraffin-based fuel grains showed similar ignition performances. The times at which the methane and oxygen solenoids appear open are slightly different in these two plots, which is attributed to the switching delay of valves and the execution delay of the command from the control system.

\subsection{Pressure oscillations}

Combustion pressure is a critical parameter that characterizes the performance of a hybrid rocket engine. Fig. 6 summarizes variations in combustion chamber pressure obtained with different fuel grains. It is evident from Fig. 6a that the combustion chamber 

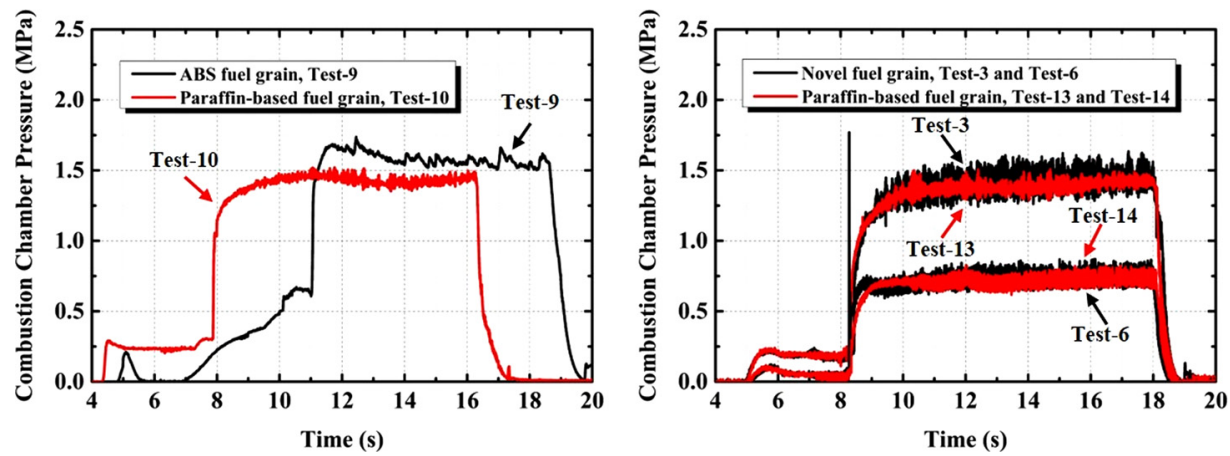

Fig. 6. Combustion chamber pressures during combustion of a) paraffin-based and ABS fuel grains, and b) novel and paraffin-based fuel grains.

pressure generated by the ABS fuel grain was slightly higher than that of the paraffin-based fuel grain, which was mainly due to the higher combustion equivalence ratio of the former (with a low regression rate) at the same mass flow rate. However, Fig. 6b shows that the average chamber pressure was substantially unaffected by the novel structure or the addition of ABS fuel. Fig. 6b demonstrates that the combustion pressure of the novel fuel grain was stable. The average pressures were approximately equal no matter at high oxidizer mass flow rate of $19 \mathrm{~g} / \mathrm{s}$ (Tests 3 and 13) or at the low mass flow rates of $9.5 \mathrm{~g} / \mathrm{s}$ (Tests 6 and 14). But the amplitude of the pressure oscillations increased in Tests 3 (Fig. 6a).

The pressure oscillations of the novel fuel grain were investigated and the results of a fast Fourier transform of the pressure spectrum are shown in Fig. 7. Similar to previous reports [41], the amplitude spectrum of pressure fluctuations for the new grain typically contained three distinct peaks at approximately 62, 130 and $320 \mathrm{~Hz}$. It is extremely significant that the amplitude spectrum of the pressure fluctuation for the novel grain was basically equivalent to that of the paraffin-based grain, although the pressure fluctuation amplitude of the former grain is slightly higher. Zilwa et al. [42] reported that these peaks correspond to low frequency instability of the hybrid engine, the Helmholtz mode and the longitudinal acoustic half-wave, respectively. We noticed that the pressure oscillation amplitude of the novel fuel grain has a maximum at $32 \mathrm{~Hz}$ with an amplitude of $1.4 \%$ of the maximum; at higher frequency around $100 \mathrm{~Hz}$, the spectrum showed an amplitude of $0.1 \%$; the longitudinal acoustic mode can be distinguished around $320 \mathrm{~Hz}$ with an amplitude of $0.1 \%$. Low frequency pressure oscillations appeared with a dominant frequency around 32 $\mathrm{Hz}$. There are two possible reasons for the low frequency instability: unsteadiness of the fuel production and coupling between the delay in the boundary layer response to changes in mass flow and thermal lag in the solid fuel. Compared with the paraffin-based fuel grain shown in Fig. 7, the amplitude of low frequency oscillations of the novel grain increased by about $180 \%$. This is likely due to chattering associated with the periodic accumulation and breakoff of ABS from the fuel surface. To sum up, the nested helical structure showed no tendency to introduce additional combustion oscillation mechanisms, although the amplitude of the original pressure oscillation is slightly amplified.

\subsection{Regression rate}

The regression rate is the most important characteristic of a solid fuel, as this parameter largely determines the thrust of the engine. Complete characterization of this quantity as a function of all relevant operational variables of the hybrid rocket engine is therefore critical for the satisfactory design of a practical system. There are several ways to express the regression rate of the solid fuel in a hybrid rocket engine, among which its expression as a function of the oxidizer mass flow flux is widely used [43]:

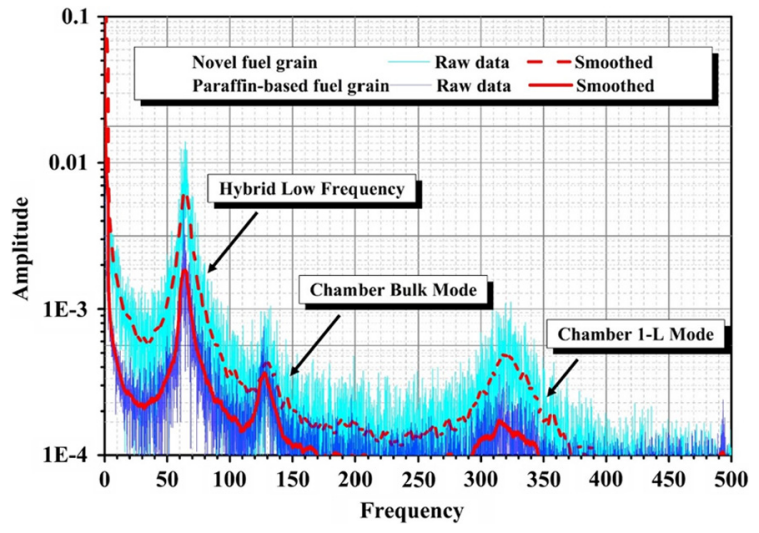

Fig. 7. Pressure spectra obtained during combustion of a paraffin-based fuel grain and the novel fuel grain.

$\dot{r}=a G_{o x}^{n}=\mathrm{a}\left(\frac{\dot{m}_{o x}}{A}\right)^{n}$,

where A represents the port area, $\dot{m}_{0 x}$ represents the mass flow rate of the oxidizer, $G_{0 x}$ represents the oxidizer mass flux, a and $\mathrm{n}$ are constants obtained by fitting the experimental results. Owing to the short working time of the hybrid rocket engine, the regression rates in this paper were calculated as average values, using the expression:

$\dot{r}=\frac{d_{f}-d_{0}}{2 t}=\frac{\sqrt{d_{0}^{2}+\frac{4\left(m_{f 0}-m_{f}\right)}{\pi \rho L}}-d_{0}}{2 t}$

where $d_{0}$ and $d_{f}$ represent the average inner diameters of the fuel grains before and after the firing test, respectively; $m_{f 0}$ and $m_{f}$ represent the qualities of the fuel grain before and after the combustion; $L$ is the length of the solid fuel grain; $t$ is the working time of the hybrid rocket engine. Because the nested grain comprised two materials, the density $\rho$ was expressed as an average value, given by:

$\rho=\rho_{p} \omega_{p}+\rho_{A B S} \omega_{A B S}$

where $\rho_{p}$ and $\omega_{p}$ represent the density and mass fraction of the nested paraffin-based fuel, respectively; $\rho_{A B S}$ and $\omega_{A B S}$ represent the analogous values of the ABS material, respectively.

Due to the different regression rate of $A B S$ and paraffin-based fuel, the mass consumption ratio of ABS continued to decrease as the combustion proceeded. Based on the experimental result, Fig. 8 shows the change in shape and inner diameter of the novel fuel grain before and after the combustion. After the firing test, the average inner diameter of the paraffin-based fuel $\left(d_{p}\right)$ changed to $45 \mathrm{~mm}$, while that of ABS fuel $\left(d_{A B S}\right)$ changed to about $40 \mathrm{~mm}$ due 

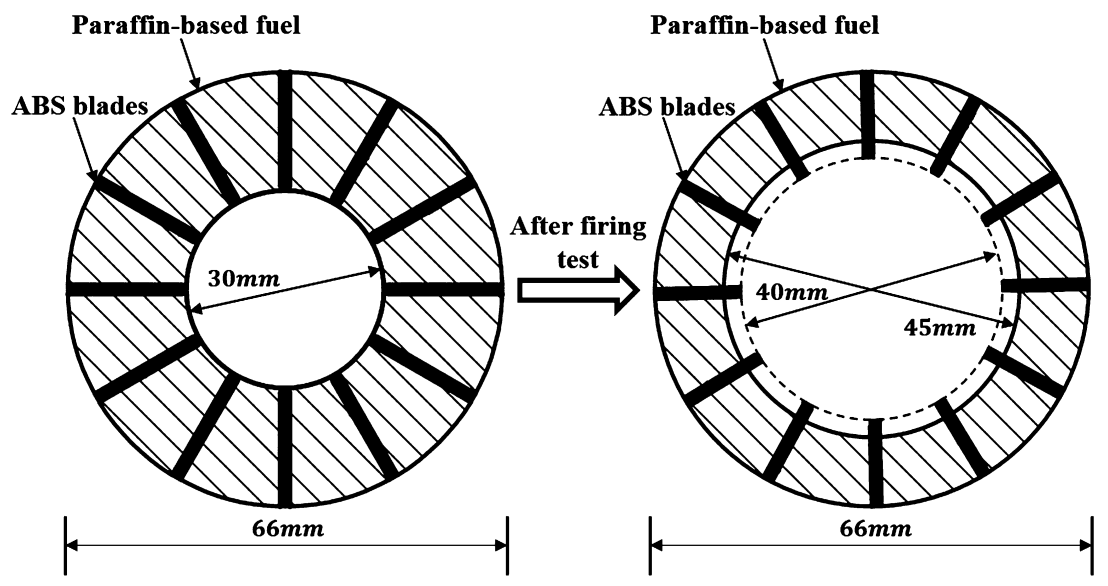

Fig. 8. Changes in shape and average inner diameter of the novel fuel grain before and after the combustion.

to the low regression rate. Owing to the initial average mass fraction of paraffin-based fuel $\left(\omega_{p}\right)$ is approximately $86 \%, \rho_{p}$ is 0.915 $\mathrm{g} / \mathrm{cm}^{3}$ and $\rho_{A B S}$ is $1.100 \mathrm{~g} / \mathrm{cm}^{3}$, the $\rho$ obtained by this method is:

$\rho=\rho_{p} \omega_{p}+\rho_{A B S} \omega_{A B S}=0.941 \mathrm{~g} / \mathrm{cm}^{3}$

And according to the change of the cross section of the novel fuel grain, the mass of ABS consumed ( $\left.m_{A B S_{\text {consumed }}}\right)$ after firing test is:

$$
\begin{aligned}
m_{A B S_{\text {consumed }}} & =\rho_{A B S} V_{A B S_{\text {consumed }}} \\
& \approx 12 \rho_{A B S} L \delta\left(\frac{d_{A B S}}{2}-\frac{d_{0}}{2}\right) \approx 12.4 \mathrm{~g}
\end{aligned}
$$

where $V_{A B S_{\text {consumed }}}$ represents the volume change of the ABS after the firing test. The mass of the paraffin-based fuel consumed after firing test $\left(m_{P_{\text {consumed }}}\right)$ is:

$$
\begin{aligned}
m_{P_{\text {consumed }}} & =\rho_{p} V_{p_{\text {consumed }}} \\
& \approx \rho_{P}\left[\frac{\pi d_{p}^{2}-\pi d_{0}^{2}}{4} L-12 L \delta\left(\frac{d_{p}}{2}-\frac{d_{0}}{2}\right)\right] \approx 85.6 g
\end{aligned}
$$

where $V_{P_{\text {consumed }}}$ represents the volume change of the paraffinbased fuel after the firing test. The mass consumption ratio of ABS $\left(\omega_{A B S_{\text {consumed }}}\right)$ during the combustion process is:

$\omega_{A B S_{\text {consumed }}}=\frac{m_{A B S_{\text {consumed }}}}{m_{A B S_{\text {consumed }}}+m_{p_{\text {consumed }}}} \approx 12.7 \%$

The average density of the fuel consumed in the combustion process ( $\left.\rho_{\text {consumed }}\right)$ is:

$\rho_{\text {consumed }}=\rho_{p} \omega_{p_{\text {consumed }}}+\rho_{A B S} \omega_{A B S_{\text {consumed }}} \approx 0.938 \mathrm{~g} / \mathrm{cm}^{3}$

Therefore, the deviation between the $\rho$ obtained by this method and $\rho_{\text {actual }}$ is about $0.4 \%$. the deviation $e$ between the $\rho$ obtained by this method and the $\rho_{\text {consumed }}$ is:

$e=\frac{\rho-\rho_{\text {consumed }}}{\rho_{\text {consumed }}} \approx 0.32 \%$

All tests were performed while keeping the inner diameter of the fuel grain basically constant and varying the mass flow rate of oxygen to ensure variations in the flux density, and Fig. 9 plots the regression rates of the nested helical grains as a function of oxidizer flux. Equations for regression rates for both the paraffinbased fuel and the novel fuel grain were obtained by fitting the experimental results, to give, respectively:

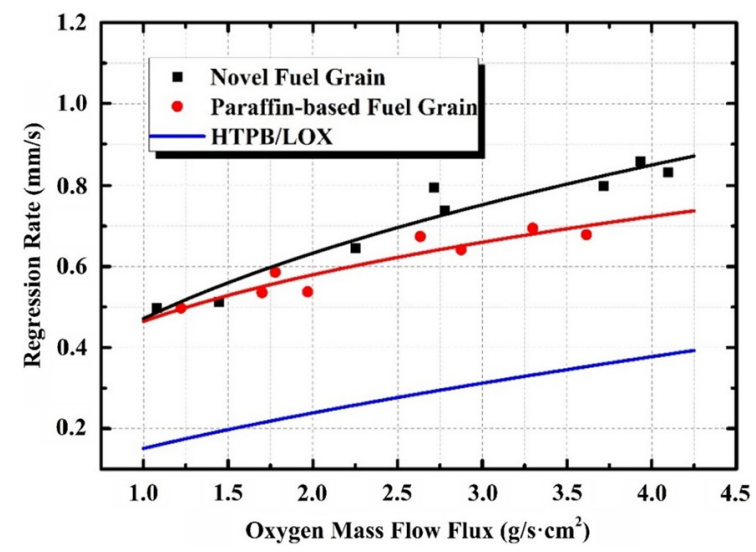

Fig. 9. Comparison of regression rates of novel fuel grains, paraffin-based fuel grains, and HTPB fuel grains (data taken from reference [1]).

$\dot{r}_{N}=0.47 G_{o x}^{0.43}$

and

$\dot{r}_{P}=0.46 G_{o x}^{0.32}$

where the regression rate is in units of $\mathrm{mm} / \mathrm{s}$, and the oxidizer mass flux is in $\mathrm{g} / \mathrm{cm}^{2}$. In laboratory-scale tests of the hybrid rocket engine with a mass flow rate of $30 \mathrm{~g} / \mathrm{s}$, the regression rate of the novel fuel grain was increased by $20 \%$ compared with that of the paraffin-based fuel grain and by $123 \%$ when compared with the HTPB fuel grain reported in [1]. These results indicate that this helical structure significantly enhanced the regression rate.

A photographic image of a typical fuel grain after a combustion test is provided in Fig. 10. The nested helical structure on the inner surface of the fuel grain, which resulted from the different burning rates of the ABS and paraffin-based fuels, verified our hypothesis that the nested helical structure could maintain throughout the combustion process. When oxidizer is injected into the combustion chamber, it is guided by the fuel grain in the axial direction just as in a standard single-bore grain. Simultaneously, the nested helical structure also induces a helical motion in the oxidizer gas along the rotational direction of the helical blades which increases the swirl strength of the internal flow. Most importantly, numerous recirculation zones may be formed at the groove between adjacent vanes, which exacerbates the radial disturbance of the gas. The initially stable laminar boundary layer is destroyed by the resulting flow instability and by vortices generated by the recirculation zone. Turbulence on the inner surface of the fuel grain will increase, and the droplet entrainment may become more intense. Eventually, the exchanges of both heat and matter between the inner surface of 


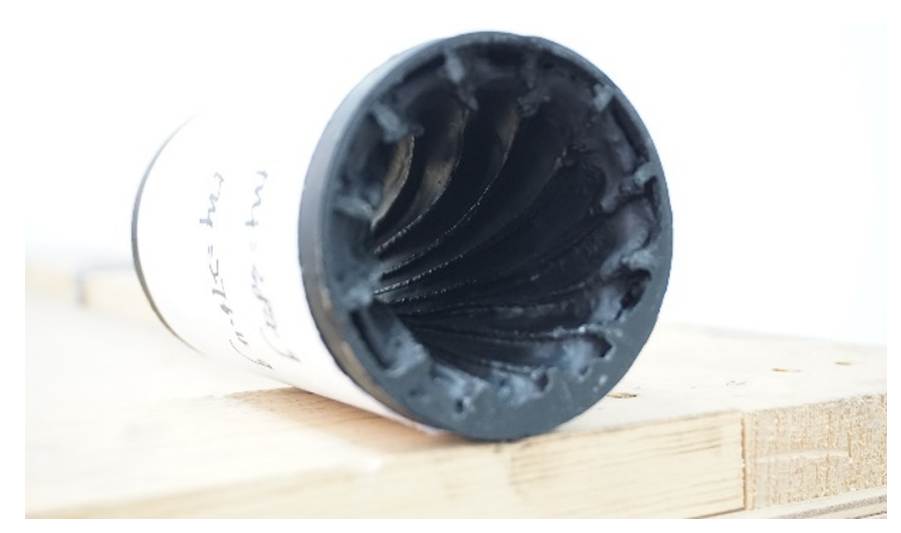

Fig. 10. Inner surface of a novel fuel grain with a nested helical structure after combustion.

the fuel grain and the main flow zone are increased, such that the regression rate is increased.

Material incompatibility may cause debonding between the ABS and paraffin-based fuel during the molding process. However, the experimental results showed that the newly designed hybrid rocket engine was not significantly affected by cracks within the fuel grain and that the structure of its inner surface of the fuel grain was basically unchanged after combustion. This result confirmed that the paraffin-based fuel grain exhibited the ability to self-repair as a result of the low surface tension and low melting point of the paraffin.

\subsection{Combustion efficiency}

Combustion efficiency is also a significant parameter for the evaluation of an engine. Owing to the nature of diffusion combustion, the combustion efficiency of hybrid rocket engines is typically lower than those of other rocket engines. Hence, it is extremely important to improve this parameter. Efficiencies based on $C^{*}$ were used for all tests. Based on the average combustion chamber pressure, $P_{c}$, and the average mass flow rate of the propellant, $\dot{m}$, the average characteristic velocity was estimated as:

$C^{*}=\frac{P_{c} A_{t}}{\dot{m}}$,

where $A_{t}$ is constant due to the short experimental time. The average $C^{*}$ values calculated for all tests are plotted in Fig. 11 against $\mathrm{O} / \mathrm{F}$ values. The theoretical combustion efficiency of pure paraffin, as calculated by Chemical Equilibrium with Applications software [44], was used as the baseline.

Fig. 11 showed that the combustion efficiency of the novel fuel grain was between $77 \%$ and $85 \%$, while that of the paraffin-based fuel grain was in the range of $75 \%-83 \%$. The average characteristic velocities of the novel grain were also higher than those of the paraffin-based grain at various $\mathrm{O} / \mathrm{F}$ ratios.

It should be pointed out that the commercial ABS used in these trials had an extremely low specific impulse due to the addition of flame retardants. Although the combustion chamber pressure generated by the ABS fuel grain was higher than that obtained from the paraffin-based fuel grain, the calculated specific impulse for the ABS engine was 143 s, which was only $60 \%-70 \%$ of the specific impulse of the paraffin-based fuel grain. Even with the low combustion performance of the ABS, the highest specific impulse obtained from the fuel grain with the nested helical structure was $242 \mathrm{~s}$, which was higher than that of the paraffin-based fuel grain. These results demonstrate from another perspective that the novel fuel grain has significant potential to increase combustion efficiency.

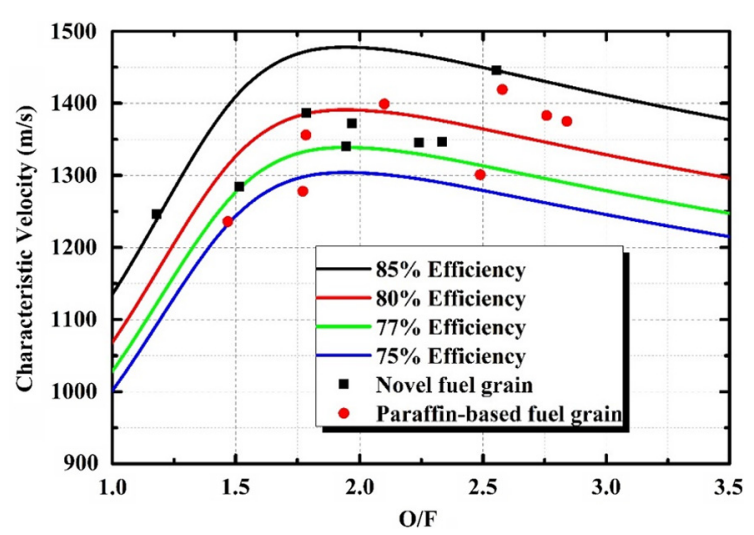

Fig. 11. Comparison of the combustion efficiencies of the paraffin-based and novel fuel grains.

Similar to the mechanism by which the regression rate was improved, the combustion efficiency was primarily increased because gas flowing through the nested helical structure formed vortices between adjacent blade protrusions. These in turn enhanced the exchanges of heat and matter between the main flow zone and the inner surface of the fuel grain. Consequently, mixing of the oxidizer and fuel was more efficient, and the burning time was increased, such that chemical reactions in the combustion chamber were more likely to go to completion.

Investigations involving either numerical simulations or experiments are needed to further examine the effect of the nested helical structure on the combustion performance. Moreover, the novel fuel grain should be further optimized to achieve better performance by adjusting parameters associated with the nested helical structure, such as helicity and blade thickness and quantity, or by varying the two materials (for example, by using ABS/HTPB).

\section{Conclusion}

A novel fuel grain composed of a paraffin-based fuel embedded in an $A B S$ substrate was designed. The ABS substrate was fabricated using 3D printing and provided a helical structural framework for the paraffin-based fuel. As a result of the difference in the regression rates of the paraffin-based and ABS fuels, the nested helical structure was maintained intact throughout the combustion process. A detailed preparation process for the novel fuel grain was developed and a series of experiments were conducted to explore the combustion performance, including the ignition characteristics, pressure oscillations, regression rate, and combustion efficiency. Pure paraffin-based fuel grain was tested as a baseline fuel and compared with the novel fuel grain. The following broad conclusions can be drawn.

1) Ignition performance of the novel fuel grain was not affected by the nested helical structure, and the ignition delay time of the novel fuel grain is less than $0.25 \mathrm{~s}$.

2) Combustion pressure of the novel fuel grain was stable, and it is highly likely that the nested helical structure did not introduce additional combustion oscillation mechanisms into the hybrid rocket engines.

3) The regression rate of the novel fuel grain was significantly improved by the nested helical structure. With an oxidizer mass flow rate of $30 \mathrm{~g} / \mathrm{s}$, the regression rate of the novel fuel grain increased by $20 \%$ compared with that of the paraffin-based fuel grain. According to the fitting equation of the regression rate, further improvements will be obtained as the oxidizer mass flux increases.

4) Because the commercial ABS material used in this work has poor combustion performance, the novel fuel grain with nested helical structure demonstrated herein has the potential for further 
improvements and is expected to further increase the combustion efficiency of hybrid rocket engines.

\section{Declaration of competing interest}

The authors declare that there is no conflict of interests regarding the publication of this article.

\section{Acknowledgements}

This work was funded in part by the National Natural Science Foundation of China (No. 11802315 and No. 11872368) and Equipment Pre-research Foundation of National Defense Key Laboratory (No. 6142701190402).

\section{References}

[1] K.K. Kuo, M.J. Chiaverini, Fundamentals of Hybrid Rocket Combustion and Propulsion, vol. 218, 2007.

[2] M.A. Karabeyoglu, D. Altman, B.J. Cantwell, Combustion of liquefying hybrid propellants: part 1, general theory, J. Propuls. Power 18 (2002) 610-620, https://doi.org/10.2514/2.5975.

[3] M.A. Karabeyoglu, B.J. Cantwell, Combustion of liquefying hybrid propellants: part 2, stability of liquid films, J. Propuls. Power 18 (2002) 621-630, https:// doi.org/10.2514/2.5976.

[4] E.T. Jens, B.J. Cantwell, G.S. Hubbard, Hybrid rocket propulsion systems for outer planet exploration missions, Acta Astronaut. 128 (2016) 119-130, https:// doi.org/10.1016/j.actaastro.2016.06.036.

[5] A.A. Chandler, An Investigation of Liquefying Hybrid Rocket Fuels with Applications to Solar System Exploration, 2012.

[6] A. Mazzetti, L. Merotto, G. Pinarello, Paraffin-based hybrid rocket engines applications: a review and a market perspective, Acta Astronaut. 126 (2016) 286-297.

[7] B.R. McKnight, Advanced Hybrid Rocket Motor Propulsion Unit for Cubesats, 2015.

[8] B. Marciniak, et al., Development of the ILR-33 "Amber" sounding rocket for microgravity experimentation, Aerosp. Sci. Technol. 73 (2018) 19-31, https:// doi.org/10.1016/j.ast.2017.11.034.

[9] M. Bouziane, A.E.M. Bertoldi, P. Milova, P. Hendrick, M. Lefebvre, Performance comparison of oxidizer injectors in a 1-kN paraffin-fueled hybrid rocket motor, Aerosp. Sci. Technol. 89 (2019) 392-406, https://doi.org/10.1016/j.ast.2019.04. 009.

[10] C. Oiknine, New perspectives for hybrid propulsion, https://doi.org/10.2514/6. 2006-4674, 2006.

[11] Y. Hirata, et al., Improvement of regression rate and combustion efficiency of high density polyethylene fuel and paraffin fuel of hybrid rockets with multisection swirl injection method, in: AIAA/ASME/SAE/ASEE Joint Propulsion Conference \& Exhibit (2011), 2011.

[12] E.T. Jens, V.A. Miller, F.S. Mechentel, B.J. Cantwell, S. Hubbard, A visual study of the combustion of high regression rate and classical hybrid rocket fuels, https://doi.org/10.2514/6.2015-3830, 2015.

[13] C. Carmicino, A. Russo Sorge, Experimental investigation into the effect of solid-fuel additives on hybrid rocket performance, J. Propuls. Power 31 (2015) 699-713, https://doi.org/10.2514/1.b35383.

[14] X. Sun, H. Tian, N. Yu, G. Cai, Regression rate and combustion performance investigation of aluminum metalized HTPB/98HP hybrid rocket motor with numerical simulation, Aerosp. Sci. Technol. 42 (2015) 287-296, https://doi.org/10. 1016/j.ast.2015.01.014.

[15] S.A. Hashim, S. Karmakar, A. Roy, Effects of Ti and Mg particles on combustion characteristics of boron-HTPB-based solid fuels for hybrid gas generator in ducted rocket applications, Acta Astronaut. 160 (2019) 125-137, https:// doi.org/10.1016/j.actaastro.2019.04.002.

[16] E. Paccagnella, F. Barato, D. Pavarin, A. Karabeyoğlu, Scaling parameters of swirling oxidizer injection in hybrid rocket motors, J. Propuls. Power 33 (2017) 1378-1394, https://doi.org/10.2514/1.b36241.

[17] Ohyama Sho, et al., A study of hybrid rockets with multi-section swirl injection method, in: 48th AIAA/ASME/SAE/ASEE Joint Propulsion Conference \& Exhibit 2012, 2012.

[18] R. Kumar, P.A. Ramakrishna, Effect of protrusion on the enhancement of regression rate, Aerosp. Sci. Technol. 39 (2014) 169-178, https://doi.org/10.1016/j.ast. 2014.09.001.
[19] X. Sun, H. Tian, G. Cai, Diameter and position effect determination of diaphragm on hybrid rocket motor, Acta Astronaut. 126 (2016) 325-333, https:/| doi.org/10.1016/j.actaastro.2016.04.029.

[20] G.D. Di Martino, S. Mungiguerra, C. Carmicino, R. Savino, Computational fluiddynamic modeling of the internal ballistics of paraffin-fueled hybrid rocket, Aerosp. Sci. Technol. 89 (2019) 431-444, https://doi.org/10.1016/j.ast.2019.04. 019.

[21] J.Y. Lestrade, J. Anthoine, A.J. Musker, A. Lecossais, Experimental demonstration of an end-burning swirling flow hybrid rocket engine, Aerosp. Sci. Technol. 92 (2019) 1-8, https://doi.org/10.1016/j.ast.2019.05.057.

[22] C. Li, G. Cai, P. Wang, H. Tian, Flow field and injector heat characteristics of hybrid rocket motor with annular-gap injector, Aerosp. Sci. Technol. 93 (2019) 105326, https://doi.org/10.1016/j.ast.2019.105326.

[23] C. Lee, Y. Na, J.-W. Lee, Y.-H. Byun, Effect of induced swirl flow on regression rate of hybrid rocket fuel by helical grain configuration, Aerosp. Sci. Technol. 11 (2007) 68-76, https://doi.org/10.1016/j.ast.2006.07.006.

[24] H. Tian, Y. Li, C. Li, X. Sun, Regression rate characteristics of hybrid rocket motor with helical grain, Aerosp. Sci. Technol. 68 (2017) 90-103, https://doi.org/10. 1016/j.ast.2017.05.006.

[25] S. Whitmore, Z. Peterson, S. Eilers, Analytical and experimental comparisons of HTPB and ABS as hybrid rocket fuels, in: 47th AIAA/ASME/SAE/ASEE Joint Propulsion Conference \& Exhibit, 2011.

[26] C. Banfield, J. Kidd, J.D. Jacob, Design and development of a 3D printed unmanned aerial vehicle, AIAA Propulsion and Energy Forum (2016), https:// doi.org/10.2514/6.2016-2029.

[27] J.E. Lyne, et al., The use of a 3-D printed, polymer matrix containing pulverized fuel in a hybrid rocket, in: Joint Propulsion Conference, 2018.

[28] S.A. Whitmore, Three-dimensional printing of "Green" fuels for low-cost small spacecraft propulsion systems, J. Spacecr. Rockets 55 (2018) 13-26, https://doi. $\operatorname{org} / 10.2514 / 1 . a 33782$.

[29] T.S. Elliott, et al., Additive manufacturing of small scale rocket grain cartridges with uniformly distributed aluminum particles, in: 52nd AIAA/SAE/ASEE Joint Propulsion Conference, 2016.

[30] C. Bauer, et al., Application of additive manufacturing in solid and hybrid grain design, in: 52nd AIAA/SAE/ASEE Joint Propulsion Conference, 2016.

[31] J. Fuller, D. Ehrlich, P. Lu, R. Jansen, J. Hoffman, Advantages of rapid prototyping for hybrid rocket motor fuel grain fabrication, in: 47th AIAA/ASME/SAE/ASEE Joint Propulsion Conference \& Exhibit, 2011.

[32] Michael Creech, et al., 3D printer for paraffin based hybrid rocket fuel grains, AIAA J. (2015), https://doi.org/10.2514/6.2015-0924.

[33] M.A. Hitt, Survey of applications of additively manufactured grains in hybrid rocket motors, in: Joint Propulsion Conference, 2018.

[34] S.A. Whitmore, Z.W. Peterson, S.D. Eilers, Comparing hydroxyl terminated polybutadiene and acrylonitrile butadiene styrene as hybrid rocket fuels, J. Propuls. Power 29 (2013) 582-592, https://doi.org/10.2514/1.b34382.

[35] S.A. Whitmore, S.D. Walker, Engineering model for hybrid fuel regression rate amplification using helical ports, J. Propuls. Power 33 (2017) 398-407, https:// doi.org/10.2514/1.b36208.

[36] S.A. Whitmore, M. Sobbi, S. Walker, High regression rate hybrid rocket fue grains with helical port structures, in: 50th AIAA/ASME/SAE/ASEE Joint Propulsion Conference and Exhibit, 2014

[37] D. Armold, et al., Test of hybrid rocket fuel grains with swirl patterns fabricated using rapid prototyping technology, in: 49th AIAA/ASME/SAE/ASEE Joint Propulsion Conference, 2013.

[38] M.J. Degges, et al., Student investigation of rapid prototyping technology for hybrid rocket motor fuel grains, in: 49th AIAA/ASME/SAE/ASEE Joint Propulsion Conference, 2013.

[39] T. Connell, G. Young, K. Beckett, D.R. Gonzalez, Enhanced solid fuel regression in a hybrid rocket employing additively manufactured fuels exhibiting novel grain port geometries, in: AIAA Scitech 2019 Forum, 2019.

[40] Y. Wu, et al., Experimental investigation of fuel composition and mix-enhancer effects on the performance of paraffin-based hybrid rocket motors, Aerosp. Sci. Technol. 82-83 (2018) 620-627, https://doi.org/10.1016/j.ast.2018.09.026.

[41] A. Karabeyoglu, G. Zilliac, B.J. Cantwell, S. DeZilwa, P. Castellucci, Scale-up tests of high regression rate paraffin-based hybrid rocket fuels, J. Propuls. Power 20 (2004) 1037-1045, https://doi.org/10.2514/1.3340.

[42] S. De Zilwa, G. Zilliac, A. Karabeyoglu, M. Reinath, Combustion oscillations in high regression rate hybrid rockets, in: 39th AIAA/ASME/SAE/ASEE Joint Propulsion Conference and Exhibit, 2003.

[43] X. Li, H. Tian, N. Yu, G. Cai, Experimental investigation of fuel regression rate in a HTPB based lab-scale hybrid rocket motor, Acta Astronaut. 105 (2014) 95-100, https://doi.org/10.1016/j.actaastro.2014.08.028.

[44] B.J. Mcbride, S. Gordon, Computer program for calculation of complex chemical equilibrium compositions and applications, Nasa Ref. Publ. 1311 (1996) 443. 